\title{
๖Atlantic Multidecadal Variability and North Atlantic Jet: A Multimodel View from the Decadal Climate Prediction Project $\mathscr{O}$
}

\author{
Paolo Ruggieri, ${ }^{\mathrm{a}, \mathrm{b}}$ Alessio Bellucci, ${ }^{\mathrm{b}}$ Dario Nicolí, ${ }^{\mathrm{b}}$ Panos J. Athanasiadis, ${ }^{\mathrm{b}}$ Silvio Gualdi, ${ }^{\mathrm{b}, \mathrm{c}}$ \\ Christophe Cassou, ${ }^{\mathrm{d}}$ Fred Castruccio, ${ }^{\mathrm{e}}$ Gokhan Danabasoglu, ${ }^{\mathrm{e}}$ Paolo Davini, ${ }^{\mathrm{f}}$ Nick Dunstone,${ }^{\mathrm{g}}$ \\ Rosemary EAde, ${ }^{\mathrm{g}}$ Guillaume Gastineau, ${ }^{\mathrm{h}}$ Ben HARvey, ${ }^{\mathrm{i}}$ LeON Hermanson, ${ }^{\mathrm{g}}$ SaÏD QAsmi, \\ Yohan Ruprich-Robert, ${ }^{\mathrm{k}}$ EMILIA SANCHEZ-Gomez, ${ }^{\mathrm{d}}$ DOUG SMITH, ${ }^{\mathrm{g}}$ SimON WiLd, ${ }^{\mathrm{k}}$ AND MATTEO ZAMPIERI ${ }^{1}$ \\ ${ }^{a}$ Department of Physics and Astronomy, University of Bologna, Bologna, Italy \\ ${ }^{\mathrm{b}}$ Centro Euro-Mediterraneo sui Cambiamenti Climatici, Bologna, Italy \\ ${ }^{\mathrm{c}}$ Istituto Nazionale di Geofisica e Vulcanologia, Rome, Italy \\ ${ }^{\mathrm{d}}$ CECI, Université de Toulouse, CNRS, CERFACS, Toulouse, France \\ ${ }^{\mathrm{e}}$ National Center for Atmospheric Research, Boulder, Colorado \\ ${ }^{\mathrm{f}}$ Istituto di Scienze dell'Atmosfera e del Clima, Consiglio Nazionale delle Ricerche, Turin, Italy \\ ${ }^{\mathrm{g}}$ Met Office, Exeter, United Kingdom \\ ${ }^{\mathrm{h}}$ UMR LOCEAN, Sorbonne Université-CNRS-IRD-MNHN, IPSL, Paris, France \\ ${ }^{\mathrm{i}}$ National Centre for Atmospheric Science, Department of Meteorology, University of Reading, Reading, United Kingdom \\ ${ }^{\mathrm{j}}$ CNRM, Université de Toulouse, Météo-France, CNRS, Toulouse, France \\ ${ }^{\mathrm{k}}$ Barcelona Supercomputing Center, Barcelona, Spain \\ ${ }^{1}$ Joint Research Centre, European Commission, Ispra, Italy
}

(Manuscript received 23 December 2019, in final form 17 September 2020)

\begin{abstract}
The influence of the Atlantic multidecadal variability (AMV) on the North Atlantic storm track and eddy-driven jet in the winter season is assessed via a coordinated analysis of idealized simulations with state-of-the-art coupled models. Data used are obtained from a multimodel ensemble of AMV \pm experiments conducted in the framework of the Decadal Climate Prediction Project component C. These experiments are performed by nudging the surface of the Atlantic Ocean to states defined by the superimposition of observed AMV \pm anomalies onto the model climatology. A robust extratropical response is found in the form of a wave train extending from the Pacific to the Nordic seas. In the warm phase of the AMV compared to the cold phase, the Atlantic storm track is typically contracted and less extended poleward and the low-level jet is shifted toward the equator in the eastern Atlantic. Despite some robust features, the picture of an uncertain and model-dependent response of the Atlantic jet emerges and we demonstrate a link between model bias and the character of the jet response.
\end{abstract}

KEYWORDS: Atmosphere-ocean interaction; Storm tracks; Multidecadal variability

\section{Introduction}

The Atlantic multidecadal variability (AMV) is a pattern of variability of the North Atlantic sea surface temperature with a period of about 60-80 years (Schlesinger and Ramankutty 1994; Kushnir 1994). The AMV has been associated with the internal variability of the climate system and linked with the multidecadal variability of the meridional overturning circulation in the North Atlantic in many previous studies (e.g., Schlesinger and Ramankutty 1994; Latif et al. 2006; Ting et al. 2009; Delworth and Mann 2000; Knight et al. 2006; Zhang 2008; Medhaug and Furevik 2011). Recent works also indicated that greenhouse gases and aerosol concentrations can play a role in

๑ Denotes content that is immediately available upon publication as open access.

Supplemental information related to this paper is available at the Journals Online website: https://doi.org/10.1175/JCLI-D-190981.s1.

Corresponding author: Paolo Ruggieri, paolo.ruggieri2@unibo.it shaping this variability (Otterå et al. 2010; Saenger et al. 2009; Swingedouw et al. 2013) and supported the idea of a mixed origin of the AMV, including forced and internal processes (Rotstayn and Lohmann 2002; Terray 2012; Ting et al. 2014; Bellucci et al. 2017).

Characterizing the impact of the AMV on the atmospheric circulation over the midlatitude North Atlantic sector is crucial for a mechanistic understanding of the variability of the coupled atmosphere-ocean system on a multidecadal time scale (Sutton et al. 2018) and for exploiting predictability on a multiannual and decadal time scale (Simpson et al. 2019; Athanasiadis et al. 2020; Smith et al. 2020). Studies that analyzed this topic using a single coupled or uncoupled model generally concluded that the positive (negative) phase of the AMV induces the negative (positive) phase of the North Atlantic Oscillation (NAO) (Msadek and Frankignoul 2009; Msadek et al. 2011; Davini et al. 2015; Peings and Magnusdottir 2014 , 2016) but raised questions regarding the robustness of details of the response and the mechanisms behind it. Some sensitivity studies based on atmospheric general circulation model (AGCM)-only simulations forced with either the tropical or the extratropical component of the AMV revealed a dominant role of the tropical component (e.g., Davini et al. 
2015). Recent studies (e.g., Ruprich-Robert et al. 2017; Simpson et al. 2019; Peings and Magnusdottir 2016) emphasized the role of the extratropical component and its imprint on the eddy-driven jet and point to a joint effect of tropical and extratropical sea surface temperatures (SSTs) on the atmospheric response. A robust assessment in a multimodel ensemble of CMIP-like historical or preindustrial coupled integrations is hampered by the documented model dependence of the representation of the AMV pattern and spectrum (Zhang and Wang 2013; Ba et al. 2014). Using idealized experiments with SST restoring in the North Atlantic basin in two coupled models (a setup very similar to the one used in this study), Ruprich-Robert et al. (2017) concluded that modelrelated uncertainties in the response of the atmospheric circulation to the AMV over the North Atlantic was a limiting factor to assess impacts on Europe and called for similar analyses in a multimodel framework.

Several studies pointed at the atmospheric response to the AMV in the Pacific sector (Dong et al. 2006; Zhang and Delworth 2007; Kucharski et al. 2016; Levine et al. 2017; Ruprich-Robert et al. 2017; Levine et al. 2018; Ruprich-Robert et al. 2018) that could in turn influence the atmospheric circulation in the Atlantic. A proposed role for the stratosphere in the atmospheric response to the AMV is a potential source of disagreement between models (Omrani et al. 2014, 2016; Peings and Magnusdottir 2016). Finally, recent works suggested a role for the extratropical component of the AMV in driving a response mediated by the North Atlantic storm track (O'Reilly et al. 2017; Kwon et al. 2020). The picture emerging from the aforementioned studies underlines the importance of combined tropical and extratropical processes in shaping an uncertain winter atmospheric response in the North Atlantic to the surface forcing imposed by the AMV.

The aim of this study is to investigate the response of the North Atlantic eddy-driven jet and storm track to a change of phase of the AMV. The interest for these specific features is driven by their relevance to Eurasian climate and by the rather blurred but central role that they take in previous studies that focused on the winter atmospheric response to AMV. The analysis is based on a set of ensemble simulations with state-ofthe-art, fully coupled climate models, following the Decadal Climate Prediction Project component C (DCPP-C; Boer et al. 2016) protocol that is described in section 2 together with methods of analysis used in this study. Models show a consistent hemispheric-scale response and identify a signature of the AMV on eddy-mean flow energy conversion and an associated response of the low-level jet over Europe and are presented in section 3. These findings corroborate our mechanistic understanding of the relationship between AMV and NAO and have implications for the impact of the AMV on European temperature and precipitation that are discussed later in section 4 .

\section{Methodology}

\section{a. Experimental setup and model data}

The analysis presented in this study is based on an ensemble of sensitivity experiments performed with seven fully coupled climate models, including six that contribute to component $\mathrm{C}$ of DCPP. The DCPP is a coordinated multimodel effort that aims at investigating climate predictability and variability on annual, multiannual, and decadal time scales (Boer et al. 2016). Component $\mathrm{C}$ in particular is aimed at understanding processes and physical mechanisms behind predictive skill on the target time scale. The experimental design is presented in Boer et al. (2016) and in Ruprich-Robert et al. (2017) and is summarized hereafter.

Two sets of model experiments, namely AMV+ and AMV - , have been performed: SSTs in the North Atlantic (from $10^{\circ}$ to $65^{\circ} \mathrm{N}$ ) are restored to a field corresponding to one standard deviation of the AMV index above (below) the 12month model climatology. The model is allowed to evolve freely outside this target region. An $8^{\circ}$-wide buffer zone is applied at the edge of the nudging area to minimize shocks and to avoid instabilities in the no-restoring region. There is no sea ice restoring and no SST restoring is performed where the sea ice fraction is greater than $15 \%$. The SST spatial pattern and the mask used are shown in Fig. 1.

An ensemble of at least 25 members is performed for each AMV phase. Each realization is integrated over a 10-yr period, and the first 11 months of integration are discarded for the analysis. This is conceptually analogous to examining winter signal in lead years 2-9 in near-term climate predictions. Ensemble members are obtained with macroperturbations (Hawkins et al. 2016), that is taking different ocean states from the DECK preindustrial control (Eyring et al. 2016) as initial conditions. All the external forcings are set to their preindustrial values (1850) with the exception of EC-Earth3P, which uses 1950 values. The main features of the seven models used in this study, including model characteristics, ensemble size, and forcing, are summarized in Table 1 . The analysis is based on a total of 4340 years of simulations (2170 for each AMV phase). Due to limited data availability, data from the HadGEM3 model are not used in Figs. 8 and 9d.

Daily data of zonal wind at $850 \mathrm{hPa}$ and geopotential height at $500 \mathrm{hPa}$ from ERA-Interim (Dee et al. 2011) on a $1^{\circ} \times 1^{\circ}$ regular longitude-latitude grid for the reference period 19792017 are used in two figures (Figs. 10 and 11).

\section{b. Definition of the $A M V$ index}

The AMV index is defined as the internal component of the observed decadal variability of a basinwide average SST. It has been computed as the difference between the annual mean of the global SST and a forced component that includes natural (solar radiation and volcanoes activity) and anthropogenic [aerosol and greenhouse gas (GHG)] radiative forcing (Ting et al. 2009). The forced component is defined as the first principal component (PC1) associated with the first signal-tonoise-maximizing empirical orthogonal function of the global, annual mean SST obtained from the CMIP5 historical runs (for the 1870-2005 period) and representative concentration pathway 8.5 simulations (RCP8.5, for the $2006-13$ period). The regression of SST onto $\mathrm{PC} 1$ is then used to estimate the spatial pattern of the forced component using the Extended Reconstructed Sea Surface Temperature (ERSST) dataset, version 4 (Huang et al. 2015) or 3 (Smith et al. 2008, used by the 

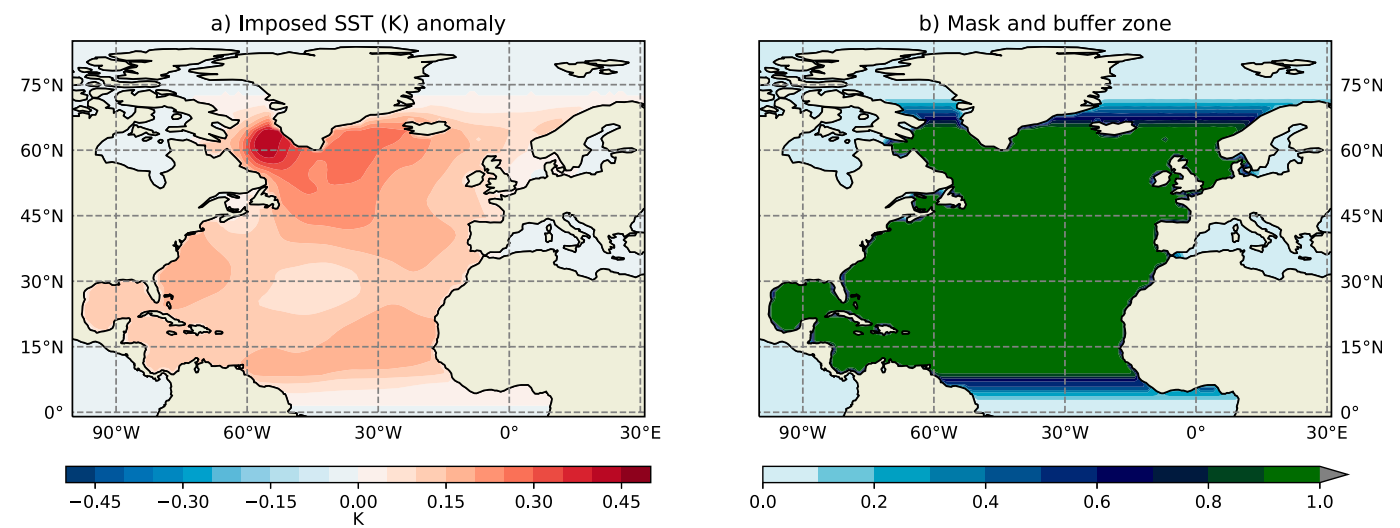

FIG. 1. (a) Sea surface temperature anomaly (K) imposed in the DCPP-C experiments. (b) Mask applied for the restoring of sea surface temperature. Note the buffer zone at the northern and southern boundaries.

CESM1 only). The internal component of the historical, global SST (hereafter $\mathrm{SST}_{\text {int }}$ ) is estimated by subtracting the forced component $(\mathrm{PC} 1 \times \mathrm{EOF})$ from the observed SST. The AMV index is then computed as a low-pass-filtered (Butterworth filter with $10-\mathrm{yr}$ cutoff period) time series of $\mathrm{SST}_{\text {int }}$ averaged over the North Atlantic $\left(75^{\circ} \mathrm{W}-7.5^{\circ} \mathrm{E}, 0^{\circ}-60^{\circ} \mathrm{N}\right)$. The AMV spatial pattern is defined by regressing the global $\mathrm{SST}_{\text {int }}$ on the AMV index for the subperiod 1900-2013. The definition of the index is a crucial step in the methodology adopted in the DCPP-C framework and arguably choices made may impact the atmospheric response in model experiments. The reader is referred to the works of Ting et al. (2009) and Boer et al. (2016) for a discussion of adopted and alternative definitions.

\section{c. Methods of analysis}

The analysis is mostly based on the difference between the ensemble means in the two AMV \pm runs. Therefore, only a linear component of the response is examined. This approach is common to previous studies (e.g., Peings and Magnusdottir 2016; Davini et al. 2015; Ruprich-Robert et al. 2017; Castruccio et al. 2019; Kwon et al. 2020). Nonetheless, it is noted that an assessment of nonlinearities in the response could enrich the picture substantially. Data used include temperature $(T)$, zonal $(u)$ and meridional $(v)$ components of wind, geopotential height $(Z), 2-\mathrm{m}$ temperature (T2m), and SST. Velocity potential and streamfunction are computed from the zonal and meridional components of the wind at either 200 or $250 \mathrm{hPa}$ (depending on data availability). Data are regridded using a bilinear interpolation onto an N80 regular Gaussian grid. Spectral coefficients of divergence and vorticity are then computed via fast Fourier transform [FFT, using the uv $2 \mathrm{dv}$ function of the Climate Data Operator (CDO); see Schulzweida (2019)]. Stream function and velocity potential are then obtained, respectively, as the inverse Laplacian of vorticity and velocity divergence. The wave activity flux is computed following Plumb (1985) and the Rossby wave source is defined as $S=-\zeta \nabla \cdot v-v_{\chi} \cdot \nabla \zeta$ where $\zeta$ is the absolute vorticity, $v$ is the horizontal wind, $v_{\chi}$ is the divergent component of the wind. Two separate components of the Rossby wave source have been analyzed, namely the vortex stretching term $(-\zeta \nabla \cdot v)$ and the vorticity advection term $\left(-v_{\chi} \cdot \nabla \zeta\right)$. To compute transient eddy quantities, FFT is applied to daily data retaining only frequencies corresponding to periods between 2 and 9 days. Filtered fields are indicated with a prime $\left({ }^{\prime}\right)$, e.g., $v^{\prime}$, is the bandpass-filtered meridional wind. The low-level transient eddy $\left(v^{\prime} T^{\prime}\right)$ is used as a proxy of low-level eddy kinetic energy and of the baroclinic energy conversion. The E vector $\mathbf{E}$ and the deformation vector $\mathbf{D}$ are defined as $\mathbf{E}=\left[\left(v^{\prime 2}-u^{\prime 2}\right) / 2, u^{\prime} v^{\prime}\right]$, $\mathbf{D}=\left(U_{x}-V_{y}, V_{x}+U_{y}\right)$, where $(U, V)$ is the time-mean wind, the primes indicate a transient quantity, and subscripts indicate derivatives in the zonal $(x)$ and meridional $(y)$ direction. Derivatives have been estimated in spherical geometry through first-order finite differences. The product $\mathbf{E} \cdot \mathbf{D}$ is used to diagnose the upper-level transfer from eddy kinetic energy

TABLE 1. List of models used in this study. Columns indicate the name of the model, atmospheric and oceanic model component and resolution, radiative forcing used in the simulation, number of ensemble members, and a reference for the model.

\begin{tabular}{llllll}
\hline \hline \multicolumn{1}{c}{ Model } & \multicolumn{1}{c}{ Atmosphere } & \multicolumn{1}{c}{ Ocean } & Forcing & Ensemble size & Reference \\
\hline CESM1 & CAM5; $1^{\circ} \times 1^{\circ}, \mathrm{L} 30$ & POP-2; $1^{\circ} \times 1^{\circ}, \mathrm{L} 60$ & 1850 & 30 & Kay et al. (2015) \\
CMCC-CM2 & CAM5; $1^{\circ} \times 1^{\circ}, \mathrm{L} 30$ & NEMO 3.6; $1^{\circ} \times 1^{\circ}, \mathrm{L} 50$ & 1850 & 32 & Cherchi et al. (2019) \\
CNRM-CM5 & ARPEGE 5.2; T127, L31 & NEMO 3.2; $1^{\circ} \times 1^{\circ}$, L42 & 1850 & 40 & Voldoire et al. (2013) \\
CNRM-CM6 & ARPEGE 6.3; T127, L91 & NEMO 3.6; $1^{\circ} \times 1^{\circ}$, L75 & 1850 & 40 & Voldoire et al. (2019) \\
EC-Earth3P & IFS; T255, L91 & NEMO 3.6; $1^{\circ} \times 1^{\circ}$, L75 & 1950 & 25 & Haarsma et al. (2020) \\
HadGEM3 & GA7 & GO8 & 1850 & 25 & Williams et al. (2018) \\
IPSL-CM6 & LMDZ; N96, L79 & NEMO; $1^{\circ} \times 1^{\circ}$, L75 & 1850 & 25 & Boucher et al. (2020) \\
\hline
\end{tabular}


Z 500 (shadings, $\mathrm{m}$ ) and Z500* (contours, m) DJF AMV+ - AMV-
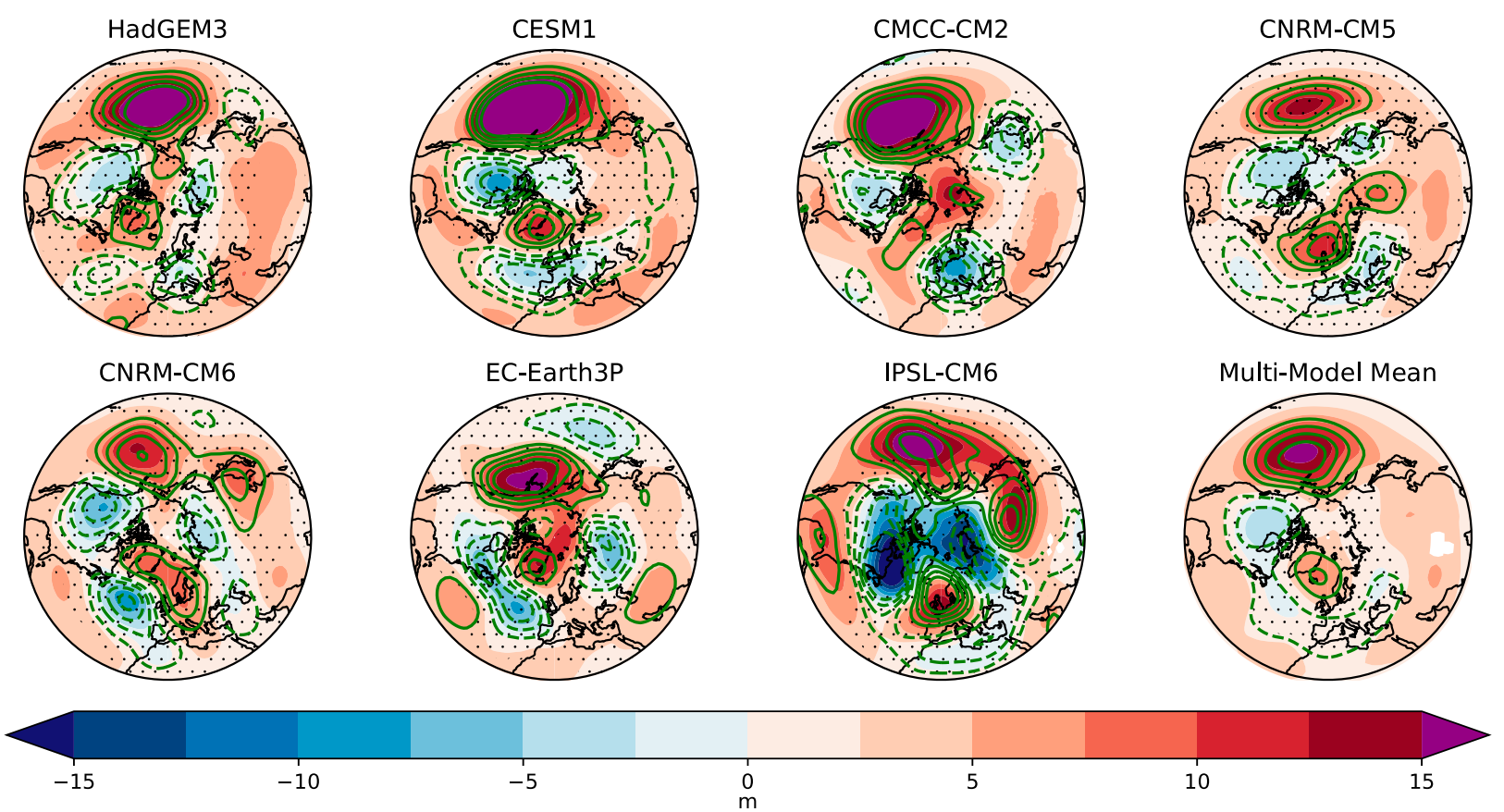

FIG. 2. Difference (AMV+ minus AMV-) of Z500 (shading; m) and Z500* (the zonally asymmetric component of Z500, displayed by green contours drawn at $\pm 2.5,5,7.5,10 \mathrm{~m}$, dashed for negative) for DJF. Stippling indicates values that are not significant at the $5 \%$ confidence level.

to kinetic energy of the mean flow. A jet latitude index (JLI) is defined following the rationale of Woollings et al. (2010): daily fields of zonal wind at $850 \mathrm{hPa}$ are averaged zonally in the sector $0^{\circ}-30^{\circ} \mathrm{W}$. The field is then low-pass-filtered with a 10 -day running mean. Then, the jet latitude is defined by locating the maximum wind between $15^{\circ}$ and $75^{\circ} \mathrm{N}$. A smooth distribution is obtained by a kernel density estimation based on Gaussian smoothing with a bandwidth parameter defined following the Silverman's rule (Silverman 1981). Note that Woollings et al. (2010) use the domain $0^{\circ}-60^{\circ} \mathrm{W}$. We choose to limit the computation of the index to smaller domain to emphasize the variability in the downstream region. This is motivated by the fact that model bias is typically stronger in this part of the Euro-Atlantic sector. The analysis performed with the index in $0^{\circ}-60^{\circ} \mathrm{W}$ yields similar results. Empirical orthogonal functions are computed using monthly mean values (DJF only) of geopotential height at $500 \mathrm{hPa}$ in the sector $75^{\circ} \mathrm{W}-15^{\circ} \mathrm{E}, 20^{\circ}-90^{\circ} \mathrm{N}$.

To compute multimodel means, fields from individual models are first regridded onto a $1^{\circ} \times 1^{\circ}$ regular (a N80 grid for streamfunction and velocity potential), global, longitudelatitude grid using bilinear interpolation. Multimodel means are computed by averaging the individual model ensemble means weighted with the respective ensemble size. Statistical significance is assessed using an unpaired Student's $t$ test. The number of degrees of freedom is taken to be equal to the size of the ensemble minus 1 . A false discovery rate (with a threshold of $5 \%$ ) is applied to account for multiplicity (Wilks 2006) in some figures (see Figs. 2, 3, 6, and 8).

\section{Results}

\section{a. Large-scale atmospheric response in the Northern Hemisphere}

The atmospheric response to the AMV is defined hereafter as the difference of the ensemble mean in AMV+ and AMVin the winter season (DJF). The magnitude of the wintertime extratropical atmospheric circulation response to AMV in the DCPP ensemble is modest: the geopotential height anomalies at $500 \mathrm{hPa}$ (Z500, shading of Fig. 2) are typically smaller than $30 \mathrm{~m}$ and organized in a wave train that peaks in the northeast Pacific. The zonally asymmetric field (Z500*, displayed with green contours in Fig. 2) highlights changes in the stationary wave pattern and is therefore useful to discuss the dynamical response of the atmosphere. All models show a substantial weakening of the Aleutian low and a smaller low over North America, analogous to the La Niña-like response that is described also in previous studies (e.g., Msadek and Frankignoul 2009; Msadek et al. 2011; Peings and Magnusdottir 2014, 2016; Davini et al. 2015; Ruprich-Robert et al. 2017). The slightly different pattern in EC-Earth3P and CNRM-CM6 in the Pacific is consistent with a different tropical response (Fig. 3). In the Atlantic, it can be noticed that models agree on the sign of the response over the Nordic seas and feature a high-latitude, blocking-like anomaly in this region. For most models (5 out of 7) this response broadly projects onto the negative phase of the NAO, remarkably IPSL-CM6 shows a neutral to positive NAO signal. Less agreement is found over the central Atlantic and Europe. There is no evidence of a robust response over the 
AMV + minus AMV- Stream Function (contours, $10^{6} \mathrm{~m}^{2} \mathrm{~s}^{-1}$ ) and Vel. Pot. (shadings, $10^{6} \mathrm{~m}^{2} \mathrm{~s}^{-1}$ )
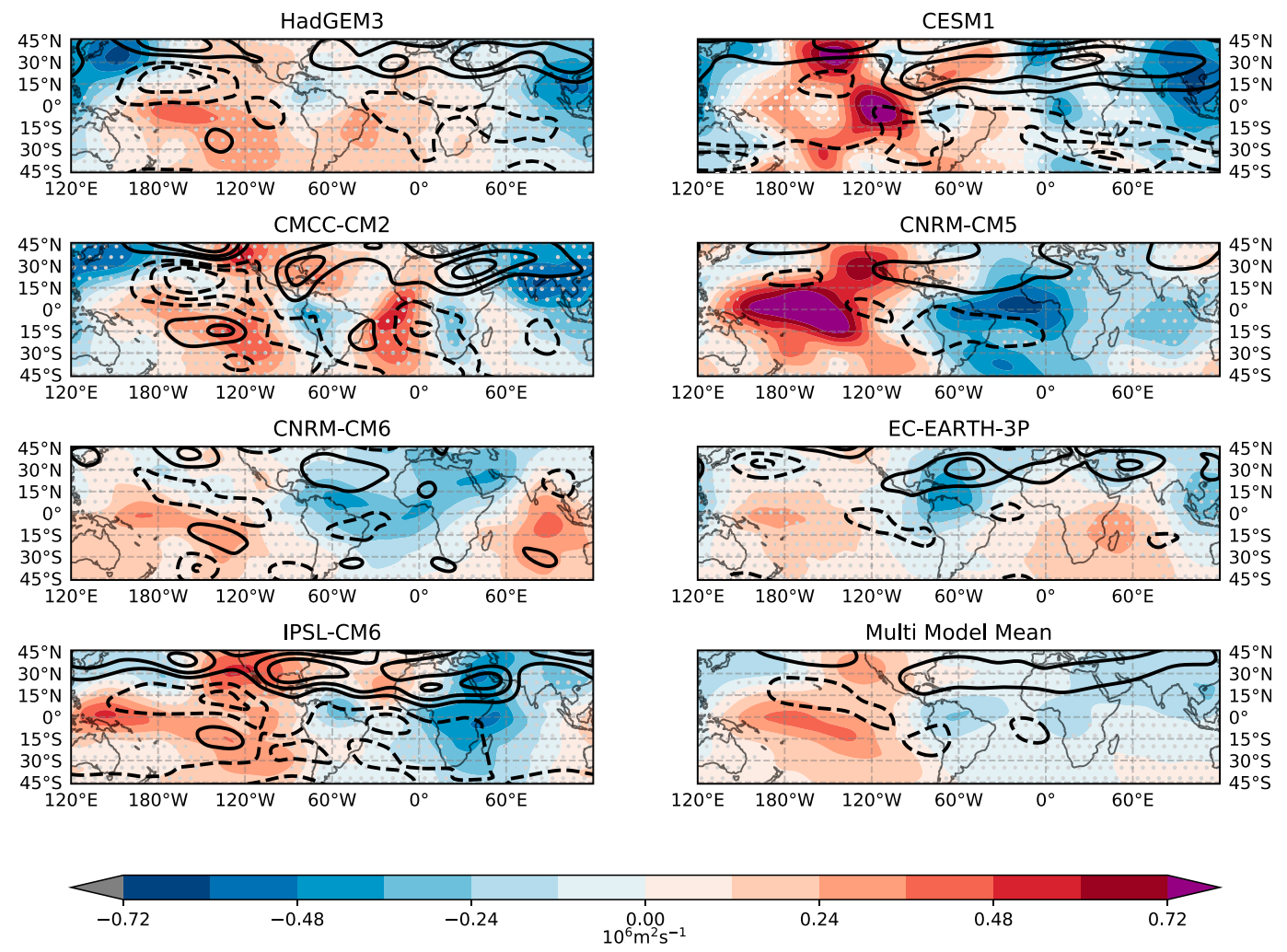

FIG. 3. Difference (AMV+ minus AMV-) of velocity potential (shading; $10^{6} \mathrm{~m}^{2} \mathrm{~s}^{-1}$ ) and streamfunctions (contours; drawn at $\left.\pm 0.6,1.2,1.8 \times 10^{6} \mathrm{~m}^{2} \mathrm{~s}^{-1}\right)$ for DJF at $200 \mathrm{hPa}(250 \mathrm{hPa}$ for EC-Earth3P). Stippling indicates values that are not significant at the $5 \%$ confidence level. A positive streamfunction indicates a clockwise rotation, and a positive potential indicates convergence.

Eurasian continent, with minor exceptions of small areas over Europe. Common features of the circulation response described above can be seen in the multimodel mean.

The adjustment of the flow in the midlatitudes of the Northern Hemisphere is found in association with a rearrangement of the tropical circulation. The latter is demonstrated by the response of the upper-level streamfunction and velocity potential shown in Fig. 3 (note that with the adopted convention a positive streamfunction indicates a clockwise rotation and a positive potential indicates convergence). All models exhibit a modulation of the Walker circulation, with reduced vertical motion in the tropical Pacific. Some models (CNRM-CM5, CNRM-CM6, IPSL-CM6, and EC-Earth3P$3 \mathrm{P})$ place the maximum anomalous upper-level divergence in the Atlantic Ocean and Africa, while others (HadGEM3, CMCC-CM2, and CESM1) have it over the Maritime Continent. Note the anticyclonic flow over the subtropical Atlantic in the Northern Hemisphere, consistent with a Gill-type response as found in previous studies (e.g., Msadek et al. 2011; Davini et al. 2015; Peings and Magnusdottir 2016) and the cyclonic flow in the northern tropical Pacific.

The multimodel ensemble mean response of the atmospheric circulation in the extratropics reveals a large degree of intermodel consensus (Fig. 4). Looking at the Pacific and North
America, models agree in the position and extent of the anomalies; the fact that all models have the same sign for the positive and the negative lobes implies a rather strong constraint on the anomalous circulation in the western Pacific. The agreement in the subtropical region, despite being poorly informative of the associated wind change, is complemented by the picture given by Figs. 2 and 3. Looking at the zonally asymmetric response of the atmosphere (Z500* in Fig. 4b) it can be seen that all models simulate the wave train from the Pacific to the Nordic seas. The negative signal that emerges in the Atlantic and Mediterranean is instead less robust, with model-to-model consistency in the sign of the anomalies limited to small-scale areas. Figure $4 c$ shows that over the North Atlantic, the multimodel mean of Z500 has a clear signal only over the Nordic seas and Greenland. The mismatch in the geographical position of the ridge in the Nordic seas and the lack of agreement at lower latitudes suggest a weak and uncertain constraint in regional changes of the Atlantic jet.

\section{b. The tropical pathway}

As noted in the introduction, a number of recent studies identified an impact of the AMV on the tropical and extratropical Pacific. The wave-activity flux (Fig. 5a) reveals a wave 
a) Z500 (m) Multi-Model AMV+ - AMV- in DJF

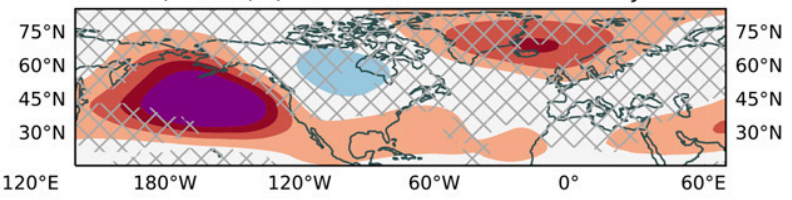

b) $2500^{*}(\mathrm{~m})$ Multi-Model AMV+ - AMV- in DJF

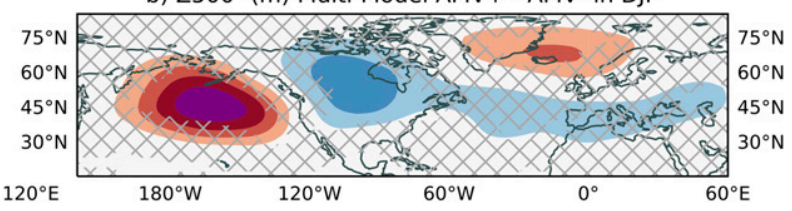

c) Z500* 6 m contour AMV+ - AMV- in DJF

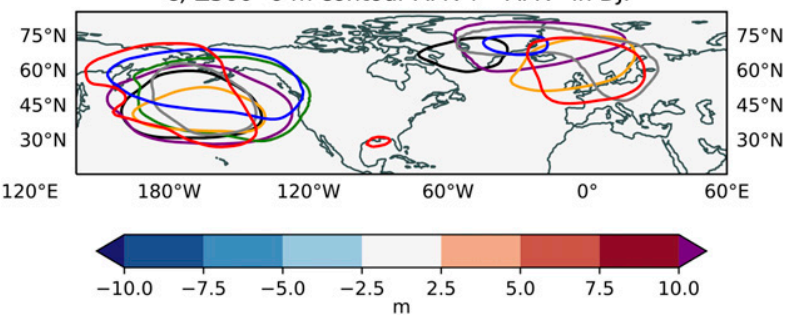

FIG. 4. (a) Multimodel mean for AMV + minus AMV - of Z500 and (b) Z500*. Hatching indicates areas where not all models used show a response with the same sign. (c) The 6-m contour of the field of Z500* in (b) for individual models.

train propagating from the subtropical Pacific into the midlatitudes. The wave-activity flux (WAF) can be associated with a modulation of the Rossby wave source explained by a modified vortex stretching term, in turn explained by a pattern of anomalous divergence/convergence of the wind (Figs. 5b,c). Note in particular the convergence in the tropical Pacific, the divergence in a tilted band of negative Rossby wave source anomaly and the structure with opposite polarity farther downstream (Fig. 5c). There is a close resemblance between the configuration found in Figs. 4 and 5 and the corresponding patterns that are observed in some La Niña events. For instance, an interesting comparison with eastern Pacific La Niña events described by Feng et al. (2017, see Figs. 5 and 6) suggests that indeed the ridge in the Nordic seas can be explained at least partly by an influence from the Pacific. A direct influence from the tropical Atlantic to the Atlantic eddy-driven jet does not emerge from the wave-activity flux, but the modifications of the upper troposphere in the equatorial Atlantic sector are arguably the primary driver of the wave train that is excited through a "Pacific bridge." Indeed, the Pacific wave train can be explained by a modification of the Walker circulation induced by SST changes in the tropical Atlantic. The signature of the Pacific bridge is rather robust and consistent in all models (not shown but see also Fig. 9). Nonetheless the lack of a signal of the $y$ component of the WAF in the Nordic seas is noticeable.

\section{c. The response of the North Atlantic jet and storm track}

Figure 6 focuses on the eddy-driven jet in the North Atlantic, here diagnosed via the zonal wind at $850 \mathrm{hPa}$. A dipolar pattern
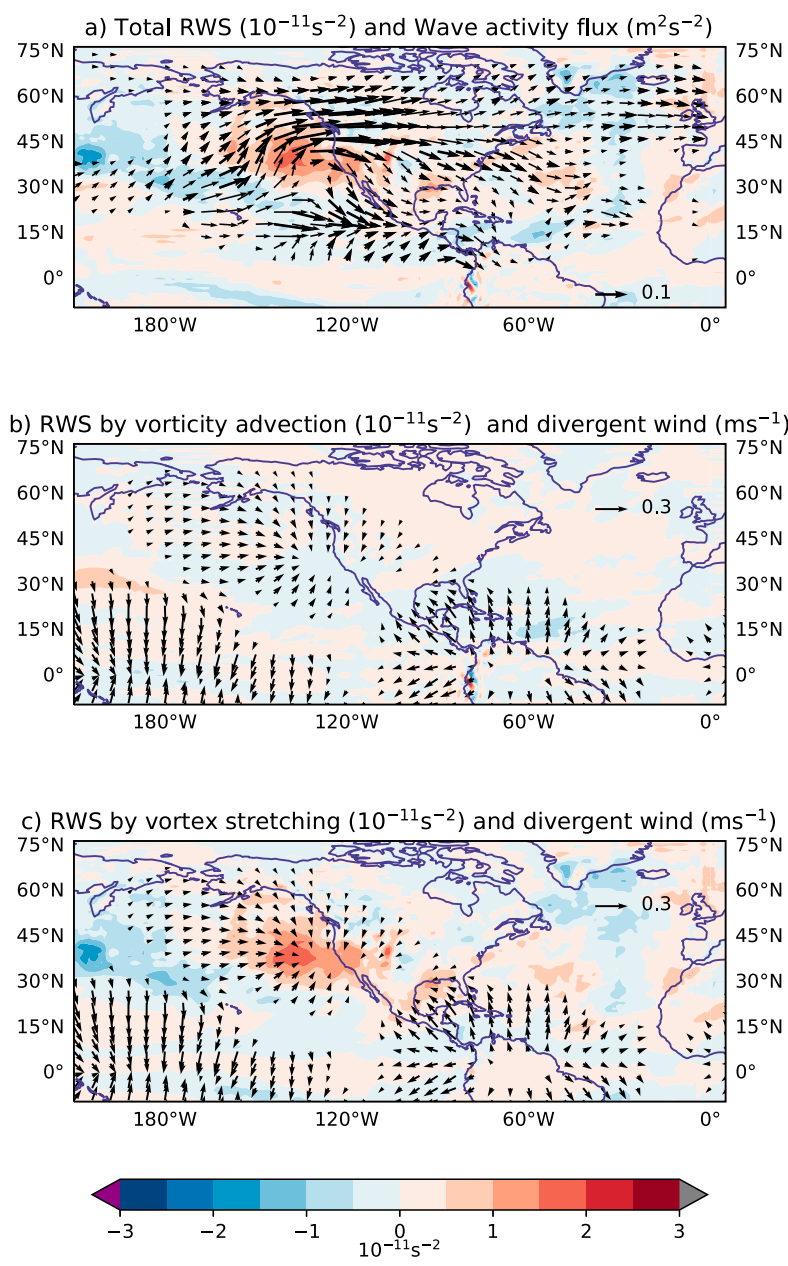

FIG. 5. (a) Multimodel mean of wave activity flux (WAF; arrows; $\mathrm{m}^{2} \mathrm{~s}^{-2}$ ) and total Rossby wave source anomaly (shading; $10^{-11} \mathrm{~s}^{-2}$ ). (b) Multimodel mean of Rossby wave source anomaly explained by vorticity advection (shading; $10^{-11} \mathrm{~s}^{-2}$ ) and divergent wind anomaly $\left(\mathrm{m} \mathrm{s}^{-1}\right)$. (c) As in (b), but for the Rossby wave source anomaly explained by the vortex stretching terms. For the WAF, vectors with modulus smaller than $0.02 \mathrm{~m}^{2} \mathrm{~s}^{-2}$ and in the latitude range $10^{\circ} \mathrm{N}-10^{\circ} \mathrm{S}$ are not displayed. Black arrows in the WAF indicate areas where all models agree on the sign of both components. For the divergent wind, vectors with modulus smaller than $0.05 \mathrm{~m} \mathrm{~s}^{-1}$ are not displayed.

compatible with a meridional jet shift and a change in the tilt of the jet is found in all cases. The order of magnitude of the signal is about $\pm 0.4 \mathrm{~m} \mathrm{~s}^{-1}$, which is generally found to be statistically significant at the $5 \%$ confidence level at least in some parts of the domain, but in other cases is not clearly distinguishable from noise. Five models out of seven show an equatorward shift of the jet in the Euro-Atlantic sector, consistent with a $\mathrm{NAO}-$ response. Although the equatorward shift identifies a common, dominant response, in CMCC-CM2, CESM1 (sharing the CAM atmospheric model) and HadGEM3 the shift of the jet is found downstream in the eastern part of the sector (also over Europe). Instead, CNRM-CM6 and EC-Earth3P 

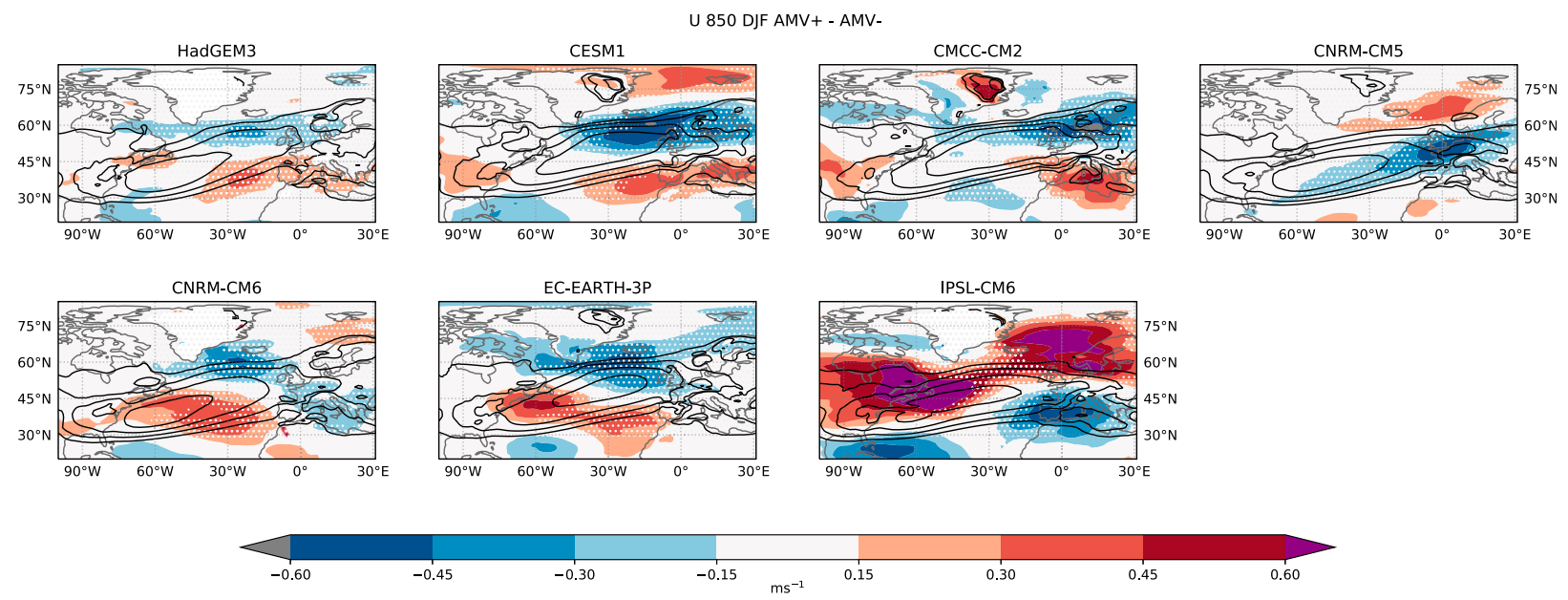

FIG. 6. Difference (AMV+ minus AMV-; shading; $\mathrm{m} \mathrm{s}^{-1}$ ) and climatology (AMV-; contours drawn at 4, 6, 8, $10 \mathrm{~m} \mathrm{~s}^{-1}$ ) of zonal wind at $850 \mathrm{hPa}$ in DJF. Stippling indicates values that are not statistically significant at the $5 \%$ confidence level.

exhibit a maximum response upstream, over the central North Atlantic. The shape of the signal in these two models suggests a pronounced reduction of the tilt of the Atlantic jet. In contrast, two models exhibit a poleward shift. In particular, IPSL-CM6 shows a strong annular signature of a poleward shift of the jet at all longitudes (not shown, see also Fig. 2). If zonally averaged over the Euro-Atlantic domain, this pattern is the opposite of what is found in the cluster of 5 models described above. A much weaker and zonally confined response is found for the CNRMCM5, where the negative branch is aligned with the climatological jet, but overall, the jet is shifted poleward. If the signal in Fig. 6 is analyzed considering a natural coordinate following the core of the climatological jet, it can be concluded that in most of the models ( 5 out of 7 ) the response of the eddy-driven jet consists in a reduction of the tilt downstream in the jet exit region, corresponding to a zonally confined equatorward shift.

It follows from this analysis that the multimodel mean (Fig. 7a) is not representative of the behavior of individual models and that models disagree on the sign and magnitude of the response of the eddy-driven jet to the AMV. On the other hand, if only models with equatorward shift are used (subset 5 in Fig. 7), then, not surprisingly, agreement is found in representing the equatorward shift. The two remaining models (subset 2) show the poleward displacement of the tail of the jet.

Figure 7 gives at least two noticeable findings. 1) Models form two clusters with consistent NAO-like response: one with NAO- (subset 5) and one with neutral/positive NAO (subset 2). 2) Models in subset 5 show on average a more tilted and poleward displaced jet in their exit region compared to model from subset 2. A similar result is found for the storm-track response (Fig. 8, results for individual models are shown in Figs. S1 and $\mathrm{S} 2$ in the online supplemental material).

The transient eddy meridional heat flux (hereafter heat flux) is shown in the top row of Fig. 8. The climatological heat flux quantifies the strength of the storm track in the seven models. The main midlatitude band (contours) outlines a region of intense heat flux and energy transfer from the mean flow to the eddies. The response of the flux to AMV can be understood considering its close relationship with local baroclinicity and with the meridional temperature gradient, which is modified by warming/cooling of the subpolar gyre prescribed in the experimental setup. Its change due to the AMV forcing is also a manifestation of large-scale shifts in the propagation of storms that go hand in hand with the changes in the waveguide of the jet (e.g., Ruggieri et al. 2020). The upstream region close to the climatological maximum, where the jet is less variable and baroclinicity is stronger, is therefore indicative of changes of the flux that are likely explained by changes of the meridional temperature gradient induced by the SST restoring. Models with the equatorward shift of the jet feature a negative heat flux anomaly in the subpolar gyre (Fig. 8b). This signal implies a less favorable environment for the development of extratropical storms during AMV+ compared to AMV-. It cannot be easily disentangled from a component induced by the jet shift, but it is coincident with an area where the temperature gradient is modulated by the AMV forcing. Notably, the two models showing the northward shift of the jet are associated with climatological maximum heat flux over the Tail of the Grand Banks (Fig. 8c) where the AMV SST anomalies (Fig. 1) reinforce the meridional SST gradient. The 5 models rather show maximum heat flux over the center of the subpolar gyre (Fig. 8b), where the AMV SST anomalies weaken the meridional SST gradient.

Synoptic eddies feed on the potential energy of the mean flow that is available along strong meridional temperature gradients and give energy back to the mean flow through eddy fluxes of horizontal momentum downstream, over the eastern North Atlantic and Europe. This stage of the energy conversion can be diagnosed via the $\mathbf{E}$. D term introduced in section 2. Positive values of $\mathbf{E} \cdot \mathbf{D}$, hereafter referred to as eddy feedback, indicate a conversion of kinetic energy from the mean flow to the eddies (Mak and Cai 1989) and vice versa. Looking at the climatology of the eddy feedback, displayed by contours in Figs. 8d, 8e, and 8f, the main negative branch 
a) Multi-model mean

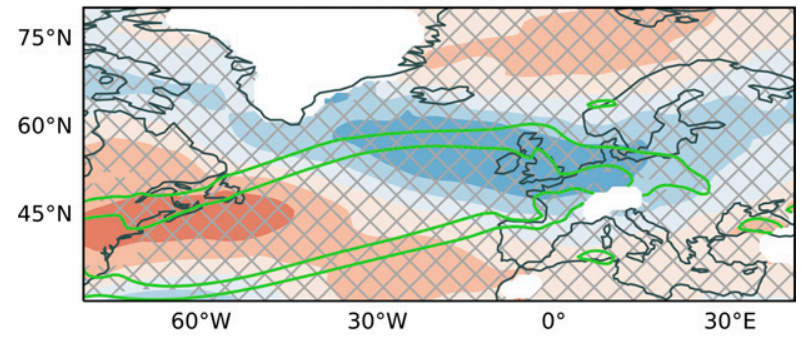

b) Subset 5 mean

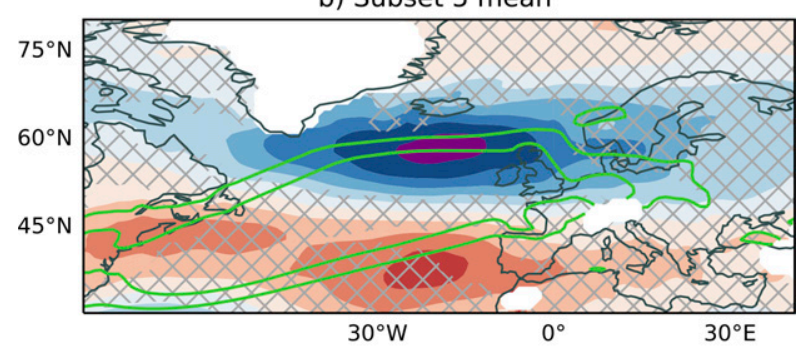

c) Subset 2 mean
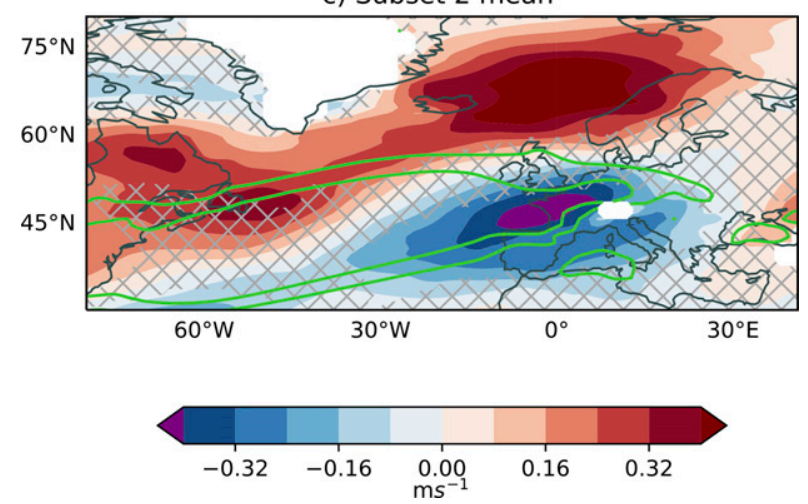

FIG. 7. (a) Multimodel mean of the response (shadings) and AMV - climatology (contours drawn at 6 and $8 \mathrm{~m} \mathrm{~s}^{-1}$ ) of the zonal wind at $850 \mathrm{hPa}$. Hatched areas indicate regions where not all models used to compute the mean indicate the same sign of the response. (b) As in (a), but using only five models (IPSL-CM6 and CNRM-CM5 excluded). (c) As in (a), but using only IPSL-CM6 and CNRM-CM5.

extending from the western North Atlantic up to the British Isles and central Europe is thus characterized by a transfer of kinetic energy from the eddies to the mean flow. Far from regions of baroclinic development and eddy growth, for example, over the eastern North Atlantic and Europe, this term is effectively representative of the total energy transfer between eddy and mean flow. Hence this "negative" region can be associated with a stage of eddy decay that acts to sustain an eddydriven jet. When looking at the response, we see that models with the NAO- response show an anomalous eddy feedback downstream in high-latitude regions (Nordic seas, Greenland, and northern Europe). The associated anomalous meridional momentum flux convergence (displayed by green contours in Fig. 8; see, in particular, Fig. 8e) where positive values imply a positive tendency on the zonal wind) shows that the eddy feedback acts to reinforce the anomalous wind pattern over Europe (Fig. 7b). In agreement with the heat flux response, these findings reveal the picture of a storm track that is more zonally contracted and less tilted in response to the AMV+ forcing. In models without the NAO- response, the anomalous eddy feedback in the Nordic seas is absent.

\section{d. A role for the atmospheric mean state}

Figure 9 summarizes some key features of the response that have been discussed in previous sections, namely, the eddydriven jet response (Fig. 9a), the deep tropical response separated into an Atlantic (Fig. 9b) and Pacific (Fig. 9c) component, and the synoptic eddies response (Fig. 9d) measured with the eddy feedback in the Nordic seas. This figure highlights that the dynamical atmospheric response in the tropics is found in all models, although with different magnitude. More specifically the missing NAO- response is not associated with a missing tropical response, whereas it comes with a missing eddy response. There is no clear association between the magnitude of the jet response and the magnitude of the eddy response, but typically models with a larger amplitude of the wind response also show a larger eddy feedback. A reasonable hypothesis is that differences discussed above are explained by similar mechanisms acting on a different mean state and variability. We have compared the two principal modes of variability of the geopotential height at $500 \mathrm{hPa}$ in the North Atlantic (Fig. 10). They are, respectively, the NAO and the eastern Atlantic (EA) pattern. The center of action is here defined as the point with the minimum (most negative) value of the EOF loading. While model bias is in some cases large and confirmed by visual inspection of the individual EOF pattern, a relationship with the sign of the response to AMV does not emerge. The PDF in the NAO-EA space is shown in Fig. 10c. This result indicates a modulation of the probability of having certain combinations of the NAO-EA. The difference is stronger for the negative EA and shows a preferred positive NAO-negative EA for models with the NAO- response. The relationship between the eddy-driven jet and NAO-EA space is detailed in Woollings et al. (2010) and this particular combination of the sign of the two EOFs is associated with the northern regime of the JLI.

The indications given by the NAO-EA space are indeed confirmed by the analysis of the JLI (Fig. 11a). Only two models (EC-Earth3P and CNRM-CM6) have three distinct peaks in the JLI distribution that are located approximately in the same positions as the observed peaks. Two models (CMCC-CM2 and CESM1) have three peaks, but the latitudes of the southern and central peaks do not correspond to the observed ones. The shoulder between $32.5^{\circ}$ and $42.5^{\circ} \mathrm{N}$ is also noticeable. CNRM-CM5 and IPSL-CM6 do not have a distinct northern peak of the jet and underestimate the occurrence of a poleward displaced jet. The JLI for the HadGEM3 model has been computed with monthly mean data of the wind. This is arguably a major difference, but a comparison with Williams et al. (2018) is reassuring. The five models that show a clear equatorward shift of the jet in response to AMV+ (in Fig. 6) also feature a reduced probability of having the jet north of 

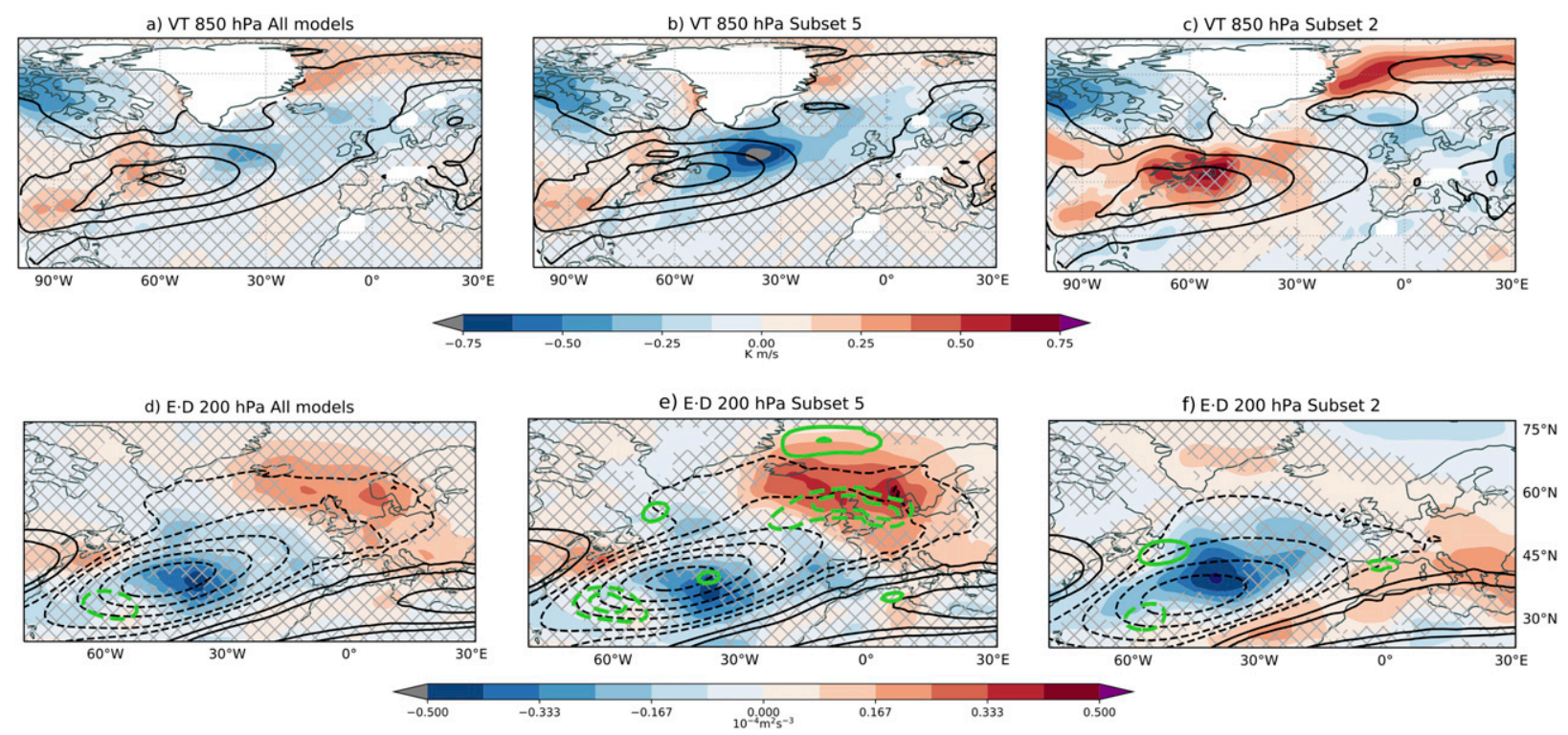

FIG. 8. (a)-(c) Difference (AMV+ minus AMV-; shading; $\mathrm{K} \mathrm{m} \mathrm{s}^{-1}$ ) and climatology (AMV-; contours drawn at $10,15,20 \mathrm{~K} \mathrm{~m} \mathrm{~s}^{-1}$ ) of $v^{\prime} T^{\prime}$ at $850 \mathrm{hPa}$ in DJF. Hatching indicates region where not all models have the same sign of the response. (d)-(f) As in (a)-(c), but for E $\cdot \mathbf{D}$ at $200 \mathrm{hPa}\left(250 \mathrm{hPa}\right.$ for EC-Earth3P; contours drawn every $\left.2 \times 10^{-4} \mathrm{~m}^{2} \mathrm{~s}^{-3}\right)$. Note that the HadGEM3 model is not used due to unavailability of data. Green contours indicate the anomalous tendency of the zonal wind explained by the eddy momentum flux (drawn at $\pm 0.25, \pm 0.35 \mathrm{~m} \mathrm{~s}^{-1} \mathrm{day}^{-1}$, dashed for negative values, solid for positive values). The field in green contours has been lightly smoothed to facilitate visualization.

$50^{\circ} \mathrm{N}$ in the AMV + compared to the AMV - (not shown). It is remarkable that all models that have a distinct northern peak of the eddy-driven jet show a negative NAO response to the $\mathrm{AMV}+$, whereas those that substantially underestimate the frequency of the northern peak do not show the NAO- response. The magnitude of the response in the band of robust easterly anomaly is found to be dependent on the fraction of days the system spends in the northern jet regime (defined as poleward of $50^{\circ} \mathrm{N}$, see Fig. 11a). The response implied by CNRM-CM5 is compatible with this relationship as a marginal case with near zero response.

The implications of this result for the modeled climatic impact of the AMV are exemplified in Fig. 12. The multimodel mean (Fig. 12a) shows little agreement over land and a small consistent signature over the western Mediterranean, North Africa, and the Middle East. The regression of the temperature response on the jet response (Fig. 12b) shows a pattern that is known to be associated with the NAO (see, e.g., Bladé et al. 2012, their Fig. 5). The temperature response over land in regions affected by the NAO variability scales at the rate of about $1 \mathrm{~K}$ per $1 \mathrm{~m} \mathrm{~s}^{-1}$. This result indicates a modulation of the temperature response in the eastern Mediterranean of about $0.3 \mathrm{~K}$, which is in agreement with results of Ruprich-Robert et al. (2017, see their Fig. 4) and that can determine the emergence of a clearly distinguishable signal. It is plausible to speculate similar impacts on precipitation and other variables affected by the NAO. Identifying and exploiting predictable signals over land has been and arguably still is a major challenge of near-term climate predictions (see, e.g., Doblas-Reyes et al. 2013; Goddard et al. 2013, their Fig. 5). The relationship in Fig. $11 \mathrm{~b}$ predicts a modulation of the temperature signal over land of a few tenths of a degree by means of a statedependent circulation response to the AMV. While no direct implications for predictions can be drawn without caution, these numbers can be relevant for operational purposes.

\section{Concluding remarks}

All models used in this study produce a similar hemisphericscale response of the atmosphere that can be summarized in a quasi-wavenumber-3 wave train extending from the Pacific to the Nordic seas (Figs. 2 and 4) and a rearrangement of the Walker circulation (Fig. 3) with La Niña-like conditions. Despite similar responses in the tropics and in the extratropical Pacific, models disagree on the eddy-driven jet response in the North Atlantic. The simulations identify a predominant behavior that is compatible with a negative NAO in response to AMV + but comes with a relatively large uncertainty and with one outlier (Fig. 11).

A nonnegligible role for the storm-track response emerges and it is compatible with the mechanism proposed by Kwon et al. (2020) who suggest that the observed modulation of the temperature gradient by the AMV in the extratropical North Atlantic leads to reduced eddy activity. The eddy feedback on the mean flow can induce the equatorward shift of eddy-driven jet. Emphasis on extratropical mechanisms has been proposed by previous studies and has been associated with the reduced temperature gradient in the subpolar gyre (e.g., Peings and Magnusdottir 2016; Ruprich-Robert et al. 2017). The response of the eddy heat flux, which is a modulation of its intensity more than a latitudinal shift, suggests a potential association 
a) Euro-Atlantic response U850

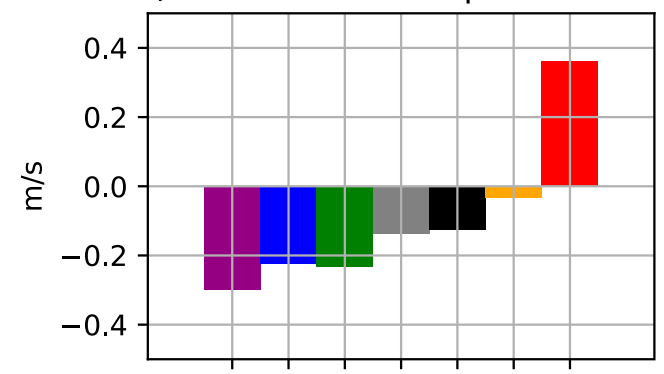

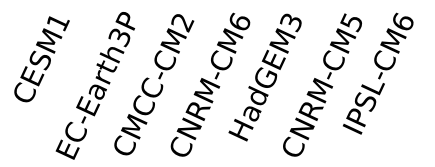

c) Pacific response $\mathrm{U} 200$

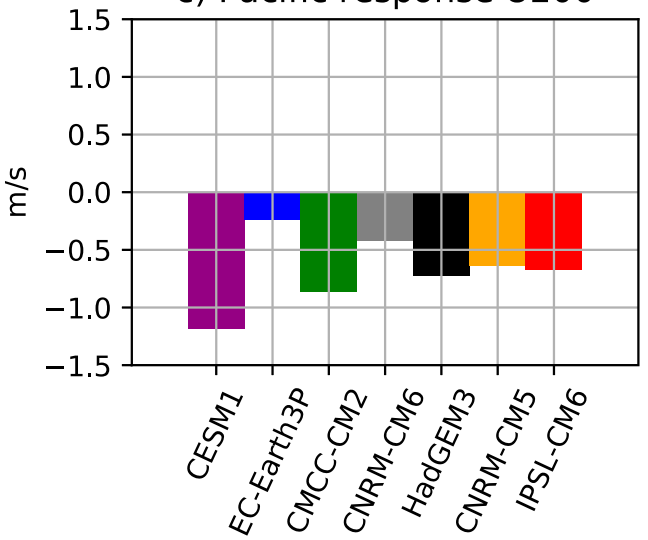

b) Tropical Atlantic response U200

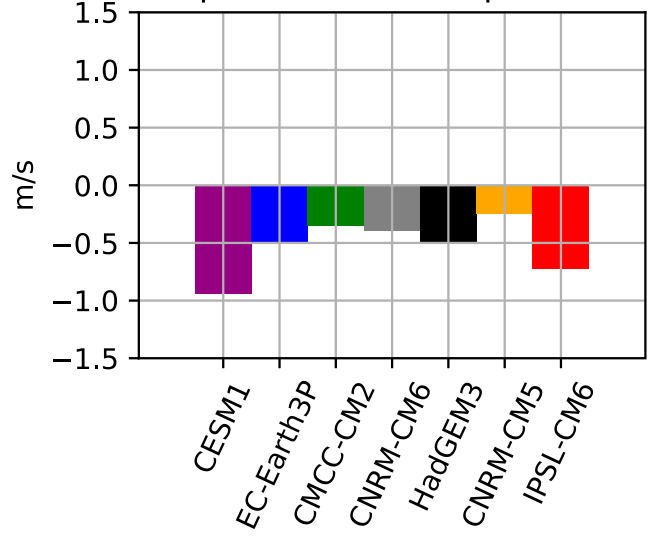

d) Eddy Feedback $200 \mathrm{hPa}$

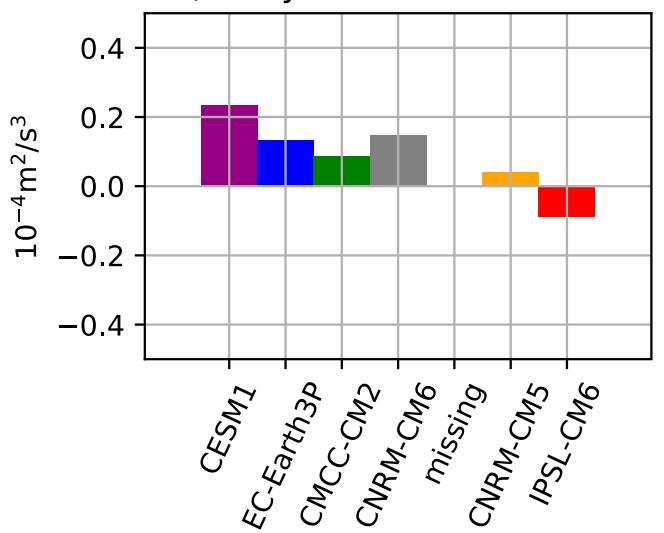

FIG. 9. (a) Zonal wind at $850 \mathrm{hPa}$ averaged in the North Atlantic and Europe $\left(50^{\circ}-70^{\circ} \mathrm{N}, 60^{\circ} \mathrm{W}-30^{\circ} \mathrm{E}\right)$. (b) Zonal wind at $200 \mathrm{hPa}(250 \mathrm{hPa}$ for EC-Earth $3 \mathrm{P})$ averaged in the tropical and subtropical North Atlantic $\left(5^{\circ}-30^{\circ} \mathrm{N}, 80^{\circ} \mathrm{W}-0^{\circ}\right)$. (c) Zonal wind at $200 \mathrm{hPa}\left(250 \mathrm{hPa}\right.$ for EC-Earth3P) averaged in subtropical Pacific $\left(15^{\circ}-45^{\circ} \mathrm{N}, 180^{\circ}-130^{\circ} \mathrm{W}\right)$. (d) Eddy feedback $(\mathbf{E} \cdot \mathbf{D})$ response in the Nordic seas $\left(45^{\circ}-75^{\circ} \mathrm{N}, 30^{\circ} \mathrm{W}-30^{\circ} \mathrm{E}\right)$.

with the variability described by Woollings et al. (2015), who find a similar behavior of the heat flux in connection with the variability of the jet on multidecadal time scales. Notably, we find that models with equatorward shift of the jet also feature the storm-track response described above, but the causality of the relationship is not straightforward. It is likely that the $\mathrm{NAO}$ - response is driven by the combined tropical and extratropical pathways discussed previously.
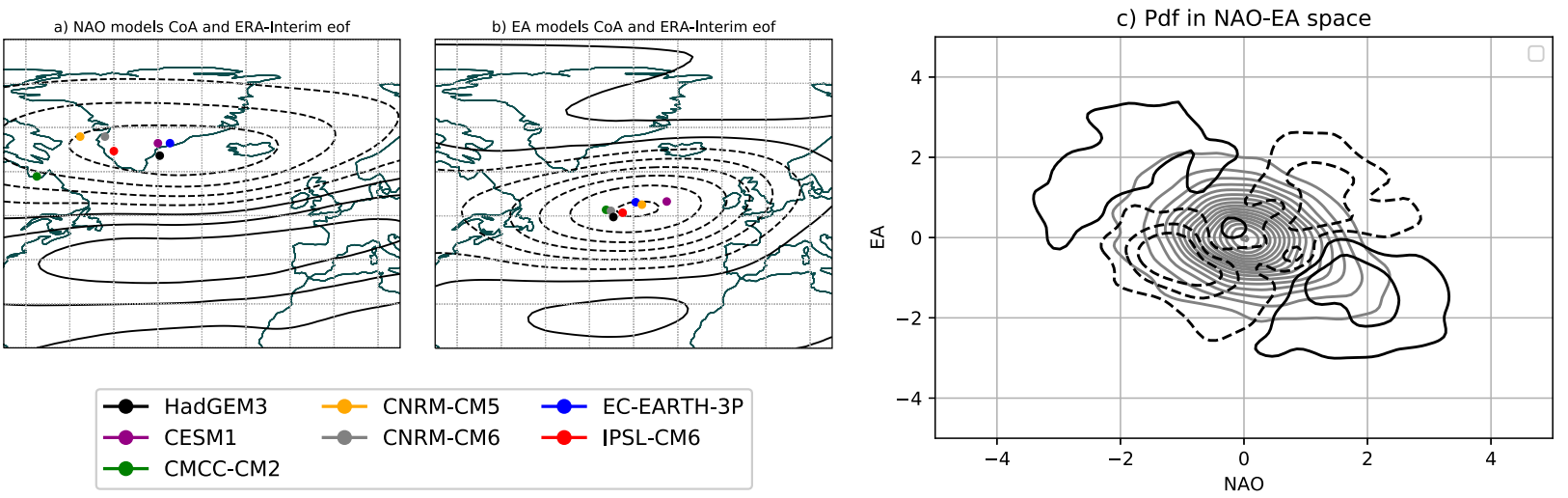

FIG. 10. Empirical orthogonal function in ERA-Interim (contours) and center of actions of models (dots) for (a) the NAO and (b) the EA. (c) PDF of NAO and EA principal components for the seven models (gray contours) and difference between the subset of five models with $\mathrm{NAO}-$ response and the two with neutral/positive NAO response (black contours). 
a) Jet Latitude Index DJF North Atlantic (AMV-)

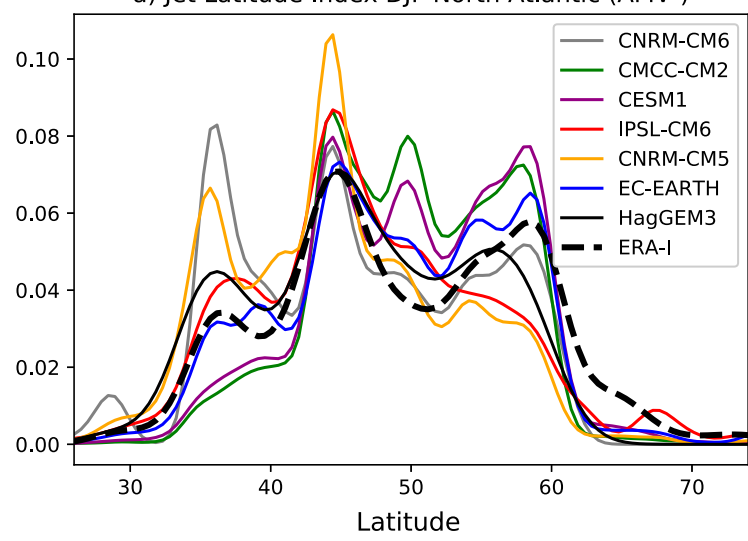

b) U850 response (50-70N 60W-30E) vs day with JLI> 50N

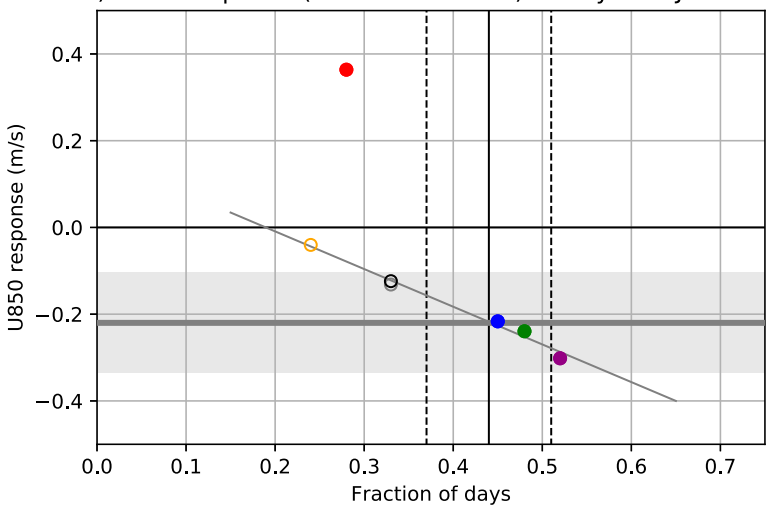

FIG. 11. (a) Smooth density of the JLI for AMV- experiments (solid lines) and ERA-Interim (bold dashed line) in DJF over the North Atlantic $\left(30^{\circ}-0^{\circ}, 15^{\circ}-75^{\circ} \mathrm{N}\right)$. (b) Relationship between the response of the zonal wind at $850 \mathrm{hPa}$ averaged in the sector $60^{\circ} \mathrm{W}-$ $30^{\circ} \mathrm{E}-50^{\circ}-70^{\circ} \mathrm{N}$ and the fraction of days with $\mathrm{JLI}>50^{\circ} \mathrm{N}$ in $\mathrm{AMV}-$. A vertical solid line indicates the $x$ value of ERA-Interim. Two dashed vertical lines mark the interval corresponding to one interannual standard deviation in ERA-Interim computed after a $10-y r$ running mean. A horizontal solid line marks the zero line. A bold, gray horizontal line indicates the value of the multimodel wind response obtained averaging the field in Fig. 7b. The shading indicates the confidence interval of the multimodel response. The thin gray line is a linear fit excluding the model with positive response (IPSL-CM6). Models with (without) a statistically significant response of the wind are indicated with a filled (empty) marker.

Discrepancies of the jet and storm-track response suggest a potential association with the atmospheric mean state that is demonstrated by the relationship found in Fig. 11. This relationship is consistent with the findings of Ruggieri et al. (2019), who found, in a very idealized environment, a clear association between magnitude of the eddies and wind response. The mean-state-response relationship found here resembles qualitatively also the one described by Smith et al. (2017) for the atmospheric response to sea ice changes. The feedback from synoptic eddies is important to shape the mean state of the jet and its variability (e.g., Hoskins et al. 1983). The northern

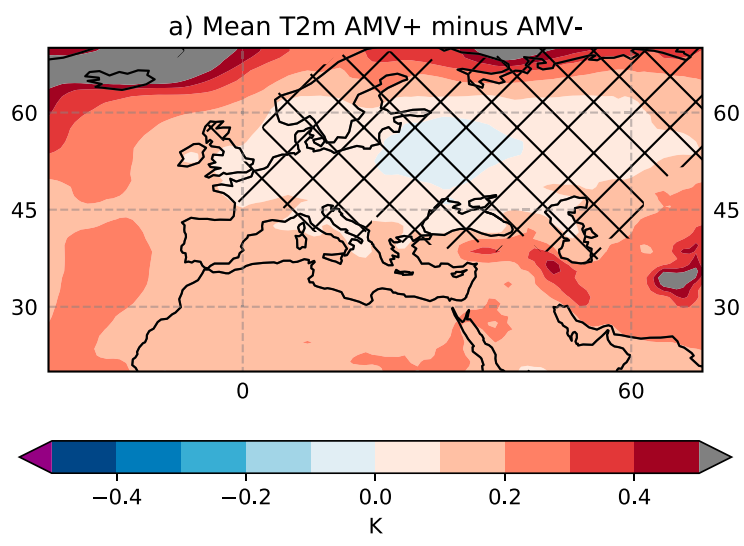

b) Regression of $\mathrm{T} 2 \mathrm{~m}$ on jet response

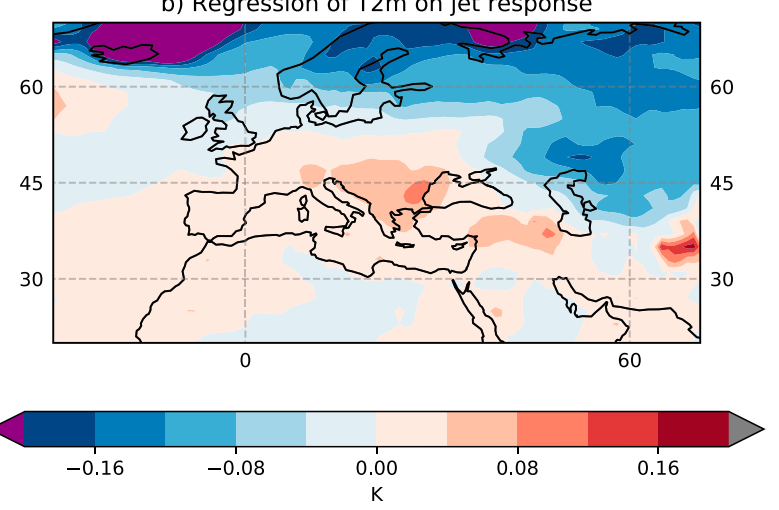

FIG. 12. (a) Multimodel mean of the 2-m temperature response (K). Hatched areas cover regions where not all models have the same sign of the response. (b) Regression of 2-m temperature response on the jet response defined as in Fig. 11b. Values displayed correspond to a change of $0.1 \mathrm{~m} \mathrm{~s}^{-1}$ of the index used in the $y$ axis of Fig. 11b. Data for the IPSL-CM6 have not been used in this figure as this is an outlier of the relationship in Fig. 11b.

regime of the JLI, that is found here to be related to the NAO response to $\mathrm{AMV}$, is linked with the combination of strong eddy heat flux events (Novak et al. 2015). Models with the missing NAO - response also have a weaker heat flux, a less tilted jet and a reduced frequency of the northern jet. It is plausible therefore that models that underestimate the intensity of the heat flux also underestimate its sensitivity to changes of the AMV phase, with a consequence for the jet response. With the above considerations and perhaps a good dose of speculation, the idea that the Nordic seas ridge is explained also by the response of the storm track to a modified temperature gradient and the conjecture of the mean-state dependence support each other. It is plausible, although not demonstrated by presented results, that the dependence of the response to the latitude of jet implies a nonlinearity of the response with respect to the intensity and sign of the SST pattern.

A displacement of the jet or more generally a modification of the Atlantic jet can be viewed as the mediator of a dynamical response of temperature (Qasmi et al. 2019) and precipitation (Simpson et al. 2019) over land. The picture given by Fig. 12 
suggests that reducing or accounting for model biases affecting the Atlantic jet will be key to deliver robust predictions of the impacts of the AMV. It also foreshadows an intrinsic uncertainty in the impact of AMV on continental Europe due to large and unpredictable atmospheric noise. The opportunity of a rather robust and consistent dynamical response in western Europe (Fig. 12b) prompts an exploitable predictability in line with the picture given by Simpson et al. (2019). Similarly, the relatively strong and robust warming in the Mediterranean, North Africa, and the Middle East is noticeable.

In summary, we find a robust large-scale extratropical response that consists in a wave train with a weakened Aleutian low and a ridge in the Nordic seas. Compared to previous analyses, in this study we take advantage of a novel protocoldriven experimental setup, explicitly designed to assess the response of the global climate system to the AMV mode, in a multimodel context. Previous analyses of the same mechanism were conducted using single-model or less idealized frameworks. The multimodel approach used in this study allows a robust characterization of the model uncertainty. The idealized character of the experimental setting allows a rather clean causal attribution of the impact of AMV on the North Atlantic jet. Results of this study ultimately depend upon the specific choices made in defining the AMV pattern, detailed in the DCPP technical note (available at https://www.wcrp-climate. org/experimental-protocol). In view of the presented results it is arguable that the equatorward shift of the jet in response to the positive phase of the AMV is explained by the combination of the atmospheric response to both tropical and extratropical SSTs and associated pathways, as neither of these two mechanisms is found to be ultimately negligible. Most models indicate a negative NAO-like response over the North Atlantic but with a relatively large uncertainty in magnitude and longitudinal position of the maximum response. This uncertainty can be linked to model biases in the position of the North Atlantic eddy-driven jet highlighting the importance of the mean state for the model response.

Acknowledgments. The authors are thankful to three anonymous reviewers for valuable comments on an early version of the manuscript. PR, AB, DN, SG, ND, RE, LH, DS, and SW were supported by the H2020 EUCP project (Grant GA 776613). ND, RE, LH, and DS were supported by the Met Office Hadley Centre Climate Programme funded by BEIS and Defra. CC, ESG, and SQ would like to thank Marie-Pierre Moine for her help in model output post-processing and publication on CMIP6 database. BH acknowledges support from the NERC North Atlantic Climate System: Integrated Study (ACSIS) project. YRR was founded by the European Union's Horizon 2020 Research and Innovation Programme in the framework of the Marie Sklodowska-Curie Grant INADEC (Grant Agreement 800154). The National Center for Atmospheric Research (NCAR) is a major facility sponsored by the U.S. National Science Foundation (NSF) under Cooperative Agreement 1852977. The NCAR contribution was supported by the U.S. NSF under the Collaborative Research EaSM2 Grant OCE-1243015 and the U.S. National Oceanic and Atmospheric Administration (NOAA) Climate
Program Office under the Climate Variability and Predictability Program Grant NA13OAR4310138. SW has received funding from the European Union's Horizon 2020 research and innovation programme under the Marie Sklodowska-Curie Grant Agreement H2020-MSCA-COFUND-2016-754433.

\section{REFERENCES}

Athanasiadis, P. J., S. Yeager, Y.-O. Kwon, A. Bellucci, D. W. Smith, and S. Tibaldi, 2020: Decadal predictability of North Atlantic blocking and the NAO. npj Climate Atmos. Sci., 3, 20, https://doi.org/10.1038/s41612-020-0120-6.

$\mathrm{Ba}, \mathrm{J}$., and Coauthors, 2014: A multi-model comparison of Atlantic multidecadal variability. Climate Dyn., 43, 2333-2348, https:// doi.org/10.1007/s00382-014-2056-1.

Bellucci, A., A. Mariotti, and S. Gualdi, 2017: The role of forcings in the twentieth-century North Atlantic multidecadal variability: The 1940-75 North Atlantic cooling case study. J. Climate, 30, 7317-7337, https://doi.org/10.1175/JCLI-D-160301.1.

Bladé, I., B. Liebmann, D. Fortuny, and G. J. van Oldenborgh, 2012: Observed and simulated impacts of the summer NAO in Europe: Implications for projected drying in the Mediterranean region. Climate Dyn., 39, 709-727, https://doi.org/10.1007/s00382-0111195-x.

Boer, G. J., and Coauthors, 2016: The Decadal Climate Prediction Project (DCPP) contribution to CMI6. Geosci. Model Dev., 9, 3751-3777, https://doi.org/10.5194/gmd-9-3751-2016.

Boucher, O., and Coauthors, 2020: Presentation and evaluation of the IPSL-CM6A-LR climate model. J. Adv. Model. Earth Syst., 12, e2019MS002010, https://doi.org/10.1029/2019MS002010.

Castruccio, F. S., Y. Ruprich-Robert, S. G. Yeager, G. Danabasoglu, R. Msadek, and T. L. Delworth, 2019: Modulation of Arctic sea ice loss by atmospheric teleconnections from Atlantic multidecadal variability. J. Climate, 32, 1419-1441, https://oi.org/ 10.1175/JCLI-D-18-0307.1.

Cherchi, A., and Coauthors, 2019: Global mean climate and main patterns of variability in the CMCC-CM2 coupled model. J. Adv. Model. Earth Syst., 11, 185-209, https://doi.org/ 10.1029/2018MS001369.

Davini, P., J. von Hardenberg, and S. Corti, 2015: Tropical origin for the impacts of the Atlantic multidecadal variability on the Euro-Atlantic climate. Environ. Res. Lett., 10, 094010, https:// doi.org/10.1088/1748-9326/10/9/094010.

Dee, D. P., and Coauthors, 2011: The ERA-Interim reanalysis: Configuration and performance of the data assimilation system. Quart. J. Roy. Meteor. Soc., 137, 553-597, https://doi.org/ 10.1002/qj.828.

Delworth, T. L., and M. E. Mann, 2000: Observed and simulated multidecadal variability in the Northern Hemisphere. Climate Dyn., 16, 661-676, https://doi.org/10.1007/s003820000075.

Doblas-Reyes, F., and Coauthors, 2013: Initialized near-term regional climate change prediction. Nat. Commun., 4, 1715, https://doi.org/10.1038/ncomms2704.

Dong, B., R. T. Sutton, and A. A. Scaife, 2006: Multidecadal modulation of El Niño-Southern Oscillation (ENSO) variance by Atlantic Ocean sea surface temperatures. Geophys. Res. Lett., 33, L08705, https://doi.org/10.1029/2006GL025766.

Eyring, V., S. Bony, G. A. Meehl, C. A. Senior, B. Stevens, R. J. Stouffer, and K. E. Taylor, 2016: Overview of the Coupled Model Intercomparison Project Phase 6 (CMIP6) experimental design and organization. Geosci. Model Dev., 9, 19371958, https://doi.org/10.5194/gmd-9-1937-2016. 
Feng, J., W. Chen, and Y. Li, 2017: Asymmetry of the winter extratropical teleconnections in the Northern Hemisphere associated with two types of ENSO. Climate Dyn., 48, 2135-2151, https://doi.org/10.1007/s00382-016-3196-2.

Goddard, L., and Coauthors, 2013: A verification framework for interannual-to-decadal predictions experiments. Climate Dyn., 40, 245-272, https://doi.org/10.1007/s00382-012-1481-2.

Haarsma, R., and Coauthors, 2020: HighresMIP versions of ECEARTH: EC-Earth3P and EC-Earth3P-HR-Description, model computational performance and basic validation. Geosci. Model Dev., 13, 3507-3527, https://doi.org/10.5194/gmd-13-3507-2020.

Hawkins, E., R. S. Smith, J. M. Gregory, and D. A. Stainforth, 2016: Irreducible uncertainty in near-term climate projections. Climate Dyn., 46, 3807-3819, https://doi.org/10.1007/s00382015-2806-8.

Hoskins, B. J., I. N. James, and G. H. White, 1983: The shape, propagation and mean-flow interaction of large-scale weather systems. J. Atmos. Sci., 40, 1595-1612, https://doi.org/10.1175/ 1520-0469(1983)040<1595:TSPAMF $>2.0 . \mathrm{CO} ; 2$.

Huang, B., and Coauthors, 2015: Extended reconstructed sea surface temperature version 4 (ERSST. v4). Part I: Upgrades and intercomparisons. J. Climate, 28, 911-930, https://doi.org/ 10.1175/JCLI-D-14-00006.1.

Kay, J. E., and Coauthors, 2015: The Community Earth System Model (CESM) large ensemble project: A community resource for studying climate change in the presence of internal climate variability. Bull. Amer. Meteor. Soc., 96, 1333-1349, https://doi.org/10.1175/BAMS-D-13-00255.1.

Knight, J. R., C. K. Folland, and A. A. Scaife, 2006: Climate impacts of the Atlantic multidecadal oscillation. Geophys. Res. Lett., 33, L17706, https://doi.org/10.1029/2006GL026242.

Kucharski, F., and Coauthors, 2016: Atlantic forcing of Pacific decadal variability. Climate Dyn., 46, 2337-2351, https:// doi.org/10.1007/s00382-015-2705-z.

Kushnir, Y., 1994: Interdecadal variations in North Atlantic sea surface temperature and associated atmospheric conditions. J. Climate, 7, 141-157, https://doi.org/10.1175/1520-0442(1994) 007<0141:IVINAS $>2.0$. CO;2.

Kwon, Y.-O., H. Seo, C. C. Ummenhofer, and T. M. Joyce, 2020: Impact of multidecadal variability in Atlantic SST on winter atmospheric blocking. J. Climate, 33, 867-892, https://doi.org/ 10.1175/JCLI-D-19-0324.1.

Latif, M., M. Collins, H. Pohlmann, and N. Keenlyside, 2006: A review of predictability studies of Atlantic sector climate on decadal time scales. J. Climate, 19, 5971-5987, https://doi.org/ 10.1175/JCLI3945.1.

Levine, A. F., M. J. McPhaden, and D. M. Frierson, 2017: The impact of the AMO on multidecadal ENSO variability. Geophys. Res. Lett., 44, 3877-3886, https://doi.org/10.1002/2017GL072524.

_ D. M. Frierson, and M. J. McPhaden, 2018: AMO forcing of multidecadal Pacific ITCZ variability. J. Climate, 31, 57495764, https://doi.org/10.1175/JCLI-D-17-0810.1.

Mak, M., and M. Cai, 1989: Local barotropic instability. J. Atmos. Sci., 46, 3289-3311, https://doi.org/10.1175/1520-0469(1989) 046<3289:LBI > 2.0.CO;2.

Medhaug, I., and T. Furevik, 2011: North Atlantic 20th century multidecadal variability in coupled climate models: Sea surface temperature and ocean overturning circulation. Ocean Sci., 7, 389-404, https://doi.org/10.5194/os-7-389-2011.

Msadek, R., and C. Frankignoul, 2009: Atlantic multidecadal oceanic variability and its influence on the atmosphere in a climate model. Climate Dyn., 33, 45-62, https://doi.org/ 10.1007/s00382-008-0452-0.
- - - and L. Z. Li, 2011: Mechanisms of the atmospheric response to North Atlantic multidecadal variability: A model study. Climate Dyn., 36, 1255-1276, https://doi.org/10.1007/ s00382-010-0958-0.

Novak, L., M. H. P. Ambaum, and R. Tailleux, 2015: The life cycle of the North Atlantic storm track. J. Atmos. Sci., 72, 821-833, https://doi.org/10.1175/JAS-D-14-0082.1.

Omrani, N.-E., N. S. Keenlyside, J. Bader, and E. Manzini, 2014: Stratosphere key for wintertime atmospheric response to warm Atlantic decadal conditions. Climate Dyn., 42, 649-663, https://doi.org/10.1007/s00382-013-1860-3.

_ - J. Bader, N. S. Keenlyside, and E. Manzini, 2016: Troposphere-stratosphere response to large-scale North Atlantic Ocean variability in an atmosphere/ocean coupled model. Climate Dyn., 46, 1397-1415, https://doi.org/10.1007/s00382-015-2654-6.

O'Reilly, C. H., S. Minobe, A. Kuwano-Yoshida, and T. Woollings, 2017: The Gulf stream influence on wintertime North Atlantic jet variability. Quart. J. Roy. Meteor. Soc., 143, 173-183, https://doi.org/10.1002/qj.2907.

Otterå, O. H., M. Bentsen, H. Drange, and L. Suo, 2010: External forcing as a metronome for Atlantic multidecadal variability. Nat. Geosci., 3, 688-694, https://doi.org/10.1038/ngeo955.

Peings, Y., and G. Magnusdottir, 2014: Forcing of the wintertime atmospheric circulation by the multidecadal fluctuations of the North Atlantic Ocean. Environ. Res. Lett., 9, 034018, https:// doi.org/10.1088/1748-9326/9/3/034018.

$\longrightarrow$, and - 2016: Wintertime atmospheric response to Atlantic multidecadal variability: Effect of stratospheric representation and ocean-atmosphere coupling. Climate Dyn., 47, 10291047, https://doi.org/10.1007/s00382-015-2887-4.

Plumb, R. A., 1985: On the three-dimensional propagation of stationary waves. J. Atmos. Sci., 42, 217-229, https://doi.org/ 10.1175/1520-0469(1985)042<0217:OTTDPO>2.0.CO;2.

Qasmi, S., C. Cassou, and J. Boé, 2019: Teleconnection processes linking the intensity of the Atlantic multidecadal variability to the climate impacts over Europe in boreal winter. J. Climate, 33, 2681-2700, https://doi.org/10.1175/JCLI-D-19-0428.1.

Rotstayn, L. D., and U. Lohmann, 2002: Tropical rainfall trends and the indirect aerosol effect. J. Climate, 15, 2103-2116, https:// doi.org/10.1175/1520-0442(2002)015<2103:TRTATI>2.0.CO;2.

Ruggieri, P., F. Kucharski, and L. Novak, 2019: The response of the midlatitude jet to regional polar heating in a simple stormtrack model. J. Climate, 32, 2869-2885, https://doi.org/10.1175/ JCLI-D-18-0257.1.

—, M. C. Alvarez-Castro, P. Athanasiadis, A. Bellucci, S. Materia, and S. Gualdi, 2020: North Atlantic circulation regimes and heat transport by synoptic eddies. J. Climate, 33, 4769-4785, https:// doi.org/10.1175/JCLI-D-19-0498.1.

Ruprich-Robert, Y., R. Msadek, F. Castruccio, S. Yeager, T. Delworth, and G. Danabasoglu, 2017: Assessing the climate impacts of the observed Atlantic multidecadal variability using the GFDL CM2.1 and NCAR CESM1 global coupled models. J. Climate, 30, 2785-2810, https://doi.org/ 10.1175/JCLI-D-16-0127.1.

—, T. Delworth, R. Msadek, F. Castruccio, S. Yeager, and G. Danabasoglu, 2018: Impacts of the Atlantic multidecadal variability on north American summer climate and heat waves. J. Climate, 31, 3679-3700, https://doi.org/10.1175/JCLI-D-17-0270.1.

Saenger, C., P. Chang, L. Ji, D. W. Oppo, and A. L. Cohen, 2009: Tropical Atlantic climate response to low-latitude and extratropical sea-surface temperature: A little ice age perspective. Geophys. Res. Lett., 36, L11703, https://doi.org/ 10.1029/2009GL038677. 
Schlesinger, M. E., and N. Ramankutty, 1994: An oscillation in the global climate system of period 65-70 years. Nature, 367, 723726, https://doi.org/10.1038/367723a0.

Schulzweida, U., 2019: CDO user guide, version 1.9.8. Climate Data Operator, 222 pp., https://code.mpimet.mpg.de/projects/ cdo/embedded/cdo.pdf.

Silverman, B. W., 1981: Using kernel density estimates to investigate multimodality. J. Roy. Stat. Soc., 43B, 97-99, https:// doi.org/10.1111/j.2517-6161.1981.tb01155.x.

Simpson, I. R., S. G. Yeager, K. A. McKinnon, and C. Deser, 2019: Decadal predictability of late winter precipitation in western Europe through an ocean-jet stream connection. Nat. Geosci., 12, 613-619, https://doi.org/10.1038/s41561-019-0391-x.

Smith, D. M., N. J. Dunstone, A. A. Scaife, E. K. Fiedler, D. Copsey, and S. C. Hardiman, 2017: Atmospheric response to Arctic and Antarctic sea ice: The importance of oceanatmosphere coupling and the background state. J. Climate, $\mathbf{3 0}$, 4547-4565, https://doi.org/10.1175/JCLI-D-16-0564.1.

— , and Coauthors, 2020: North Atlantic climate far more predictable than models imply. Nature, 583, 796-800, https:// doi.org/10.1038/s41586-020-2525-0.

Smith, T. M., R. W. Reynolds, T. C. Peterson, and J. Lawrimore, 2008: Improvements to NOAA's historical merged landocean surface temperature analysis (1880-2006). J. Climate, 21, 2283-2296, https://doi.org/10.1175/2007JCLI2100.1.

Sutton, R., G. McCarthy, J. Robson, B. Sinha, A. Archibald, and L. Gray, 2018: Atlantic multidecadal variability and the UK ACSIS program. Bull. Amer. Meteor. Soc., 99, 415-425, https:// doi.org/10.1175/BAMS-D-16-0266.1.

Swingedouw, D., J. Mignot, S. Labetoulle, E. Guilyardi, and G. Madec, 2013: Initialisation and predictability of the AMOC over the last 50 years in a climate model. Climate Dyn., 40, 2381-2399, https://doi.org/10.1007/s00382-012-1516-8.

Terray, L., 2012: Evidence for multiple drivers of North Atlantic multi-decadal climate variability. Geophys. Res. Lett., 39, L19712, https://doi.org/10.1029/2012GL053046.
Ting, M., Y. Kushnir, R. Seager, and C. Li, 2009: Forced and internal twentieth-century SST trends in the North Atlantic. J. Climate, 22, 1469-1481, https://doi.org/10.1175/2008JCLI2561.1.

,-- , and C. Li, 2014: North Atlantic multidecadal SST oscillation: External forcing versus internal variability. J. Mar. Syst., 133, 27-38, https://doi.org/10.1016/j.jmarsys.2013.07.006.

Voldoire, A., and Coauthors, 2013: The CNRM-CM5. 1 global climate model: Description and basic evaluation. Climate Dyn., 40, 2091-2121, https://doi.org/10.1007/s00382-011-1259-y.

- and Coauthors, 2019: Evaluation of CMIP6 deck experiments with CNRM-CM6-1. J. Adv. Model. Earth Syst., 11, 21772213, https://doi.org/10.1029/2019MS001683.

Wilks, D., 2006: On "field significance" and the false discovery rate. J. Appl. Meteor. Climatol., 45, 1181-1189, https://doi.org/ 10.1175/JAM2404.1.

Williams, K. D., and Coauthors, 2018: The Met Office Global Coupled Model 3.0 and 3.1 (GC3.0 and GC3.1) configurations. J. Adv. Model. Earth Syst., 10, 357-380, https://doi.org/ 10.1002/2017MS001115.

Woollings, T., A. Hannachi, and B. Hoskins, 2010: Variability of the North Atlantic eddy-driven jet stream. Quart. J. Roy. Meteor. Soc., 136, 856-868, https://doi.org/10.1002/qj.625.

- C. Franzke, D. Hodson, B. Dong, E. A. Barnes, C. Raible, and J. Pinto, 2015: Contrasting interannual and multidecadal NAO variability. Climate Dyn., 45, 539-556, https:/doi.org/ 10.1007/s00382-014-2237-y.

Zhang, L., and C. Wang, 2013: Multidecadal North Atlantic sea surface temperature and Atlantic meridional overturning circulation variability in CMIP5 historical simulations. J. Geophys. Res. Oceans, 118, 5772-5791, https://doi.org/10.1002/jgrc.20390.

Zhang, R., 2008: Coherent surface-subsurface fingerprint of the Atlantic meridional overturning circulation. Geophys. Res. Lett., 35, L20705, https://doi.org/10.1029/2008GL035463.

_ and T. L. Delworth, 2007: Impact of the Atlantic multidecadal oscillation on North Pacific climate variability. Geophys. Res. Lett., 34, L23708, https://doi.org/10.1029/2007GL031601. 